\title{
Case Study With a Participatory Approach: Rethinking Pragmatics of Stakeholder Engagement for Implementation Research
}

Catherine Hudon, $M D, P b D^{1}$

Maud-Christine Chouinard, RN, $\mathrm{PbD}^{2}$

Matbieu Bisson, $M A^{1}$

Alya Danish, $P b D^{1}$

Marlène Karam, $P b D^{2}$

Ariane Girard, $R N, P b D^{1}$

Pierre-Luc Bossé, MSW

Mireille Lambert, $M A^{3}$

'Department of Family Medicine and Emergency Medicine, University of Sherbrooke, Sherbrooke, Quebec, Canada

${ }^{2}$ Faculty of Nursing, University of Montreal, Montreal, Quebec, Canada

${ }^{3}$ Integrated University Health and Social Services Centre, Chicoutimi, Quebec, Canada

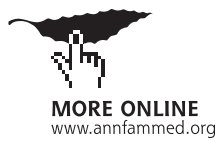

Conflicts of interest: authors report none.

\section{CORRESPONDING AUTHOR}

Catherine Hudon

Department of Family Medi-

cine and Emergency Medicine

University of Sherbrooke,

Pavillon Z7-Rm 3007

3001, 12e Ave N

Sherbrooke QC, Canada J1H 5N4

Catherine.Hudon@USherbrooke.ca

\begin{abstract}
The case study design is particularly useful for implementation analysis of complex health care innovations in primary care that can be influenced by the context of dynamic environments. Case studies may be combined with participatory approaches where academics conduct joint research with nonacademic stakeholders, to foster translation of findings results into practice. The aim of this article is to clarify epistemological and methodological considerations of case studies with a participatory approach. It also aims to propose best practice recommendations when using this case study approach. We distinguish between the participatory case study with full co-construction and co-governance, and the case study with a participatory approach whereby stakeholders are consulted in certain phases of the research. We then compare the epistemological posture of 3 prominent case study methodologists, Yin, Stake, and Merriam, to present the epistemological posture of case studies with a participatory approach. The relevance, applications, and procedures of a case study with a participatory approach methodology are illustrated through a concrete example of a primary care research program (PriCARE). We propose 12 steps for designing and conducting a case study with a participatory approach that may help guide researchers in the implementation analysis of complex health care innovations in primary care.
\end{abstract}

Ann Fam Med 2021;19:540-546. https://doi.org/10.1370/afm.2717.

\section{BACKGROUND}

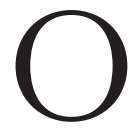
ver the last 40 years, case study research has become increasingly popular and has evolved rapidly in many disciplines. By allowing in-depth analysis of complex phenomena in real-world contexts, ${ }_{1}$ the case study design is particularly useful in health services research, ${ }^{2}$ for implementation analysis of complex interventions that can be influenced by the context of dynamic environments. ${ }^{3}$ Public health and primary care research encourage a participatory approach because involvement of stakeholders fosters translation of research findings into practice. ${ }^{4}$ This was the case of the PriCARE primary care research program. In this multijurisdictional Canadian study, the research team and stakeholders aimed to evaluate the implementation of a case management intervention in 10 primary care clinics, for frequent users of health care services with chronic diseases and complex care needs. ${ }^{5,6}$ It is important to first distinguish the case study with a participatory approach from the participatory case study before proceeding with the example of the PriCARE program.

\section{Participatory Research and the Case Study}

Participatory research is a systematic inquiry whereby academics conduct joint research with nonacademic partners affected by the issue being studied, for purposes of education and taking action or promoting social change. ${ }^{7,8}$ Participatory research conducted for empowerment or social change relies on the transformative/postmodern interpretative paradigm, in which knowledge is not neutral and reflects the power and 
social relationships within a society. The purpose of knowledge construction is to help people improve society. ${ }^{9}$ Each phase of the research process is an opportunity to create knowledge through a collaborative effort to develop or refine the research questions, select the methodology, develop data collection methods and tools, choose outcome measures, interpret findings, craft the message, and disseminate the results, feasibility, and outcomes. ${ }^{4}$ Rosemary C. Reilly, PhD, MEd ${ }^{10}$ proposes that a case study may adopt a participatory focus with full co-governance where participants are fully involved as contributing researchers in all phases of the research process, from conceptualization of the study to write-up and dissemination of the findings.

Within the different participatory research approaches, the transformational intent of stakeholder involvement may, however, range from empowerment to more pragmatic considerations. The case study with a participatory approach may be adopted to facilitate knowledge translation and practice changes ${ }^{4}$ in the implementation of a complex intervention such as case management, where several components interact with each other and with their context, and where there are multiple highly adaptable effects. ${ }^{11}$ The intensity of stakeholder involvement will vary from full co-construction and involvement in all stages of the research to involvement or consultation in only certain phases of the research, balancing stakeholder engagement and availability. The participatory case study with a full co-governance structure relies on the transformative/ postmodern interpretative paradigm, but what are the epistemological assumptions of the case study with a participatory approach? What steps should be taken to ensure the validity of this approach when applied to the case study? In this article, we aim to clarify epistemological and methodological considerations of case studies with a participatory approach. We also propose best practice recommendations when applying this approach to the case study.

\section{EPISTEMOLOGICAL ASSUMPTIONS OF 3 PROMINENT CASE STUDY METHODOLOGISTS}

Three prominent case study methodologists—-Robert K. Yin, PhD, Robert E. Stake, PhD, and Sharan B. Merriam, MEd, EdD—brought differing perspectives to move case study knowledge forward in educational and social science research. All 3 provided definitions, designs, applications, and procedures to follow when conducting case study research. ${ }^{12}$ Table 1 summarizes and compares their epistemological positions and assumptions, which we discuss in more detail below.

\begin{tabular}{|c|c|c|c|c|}
\hline Methodologist & $\begin{array}{l}\text { Epistemological } \\
\text { Position }\end{array}$ & Reality Assumptions & $\begin{array}{l}\text { Knowledge } \\
\text { Assumptions }\end{array}$ & $\begin{array}{l}\text { Methodological } \\
\text { Assumptions }\end{array}$ \\
\hline Robert K. Yin, PhD & Postpositivism & $\begin{array}{l}\text { Reality exists, but we can- } \\
\text { not know it perfectly. } \\
\text { Reality is governed by } \\
\text { natural, causal, or other } \\
\text { laws, but they cannot be } \\
\text { absolutely known. }\end{array}$ & $\begin{array}{l}\text { Knowledge is the result of the } \\
\text { combination of experimen- } \\
\text { tations leading to a closer } \\
\text { approximation of actual } \\
\text { mechanisms. }\end{array}$ & $\begin{array}{l}\text { All methods have their limits, so } \\
\text { both quantitative and qualita- } \\
\text { tive methods are needed to } \\
\text { generate empirical evidence } \\
\text { and test plausible rival } \\
\text { hypotheses. }\end{array}$ \\
\hline Robert E. Stake, PhD & Constructivism & $\begin{array}{l}\text { Multiple socially con- } \\
\text { structed realities are built } \\
\text { through interactions with } \\
\text { others and human lived } \\
\text { experiences. }\end{array}$ & $\begin{array}{l}\text { Human experience can be } \\
\text { known, and each human } \\
\text { knows his/her own experi- } \\
\text { ence of the real. }\end{array}$ & $\begin{array}{l}\text { Qualitative methods need } \\
\text { to capture the diversity of } \\
\text { realities through a deep } \\
\text { understanding of peoples' } \\
\text { perspectives and experiences } \\
\text { regarding a specific situation } \\
\text { or phenomenon. }\end{array}$ \\
\hline $\begin{array}{l}\text { Sharan B. Merriam, } \\
\text { MEd, EdD }\end{array}$ & $\begin{array}{l}\text { Constructivist } \\
\text { pragmatism }\end{array}$ & $\begin{array}{l}\text { Reality is constructed } \\
\text { through meanings } \\
\text { and understandings } \\
\text { developed socially and } \\
\text { experientially. }\end{array}$ & $\begin{array}{l}\text { Human experience can be } \\
\text { known, and each human } \\
\text { knows his/her own experi- } \\
\text { ence of the real. The finality } \\
\text { of knowledge is to address } \\
\text { concrete problems and pro- } \\
\text { vide answers or direction to } \\
\text { progress. The truth will be } \\
\text { what works in practice. }\end{array}$ & $\begin{array}{l}\text { All methods are considered. } \\
\text { What is important is to guide } \\
\text { the research process by the } \\
\text { principles of ethical and sci- } \\
\text { entific rigor, and to clarify } \\
\text { hypotheses. }\end{array}$ \\
\hline $\begin{array}{l}\text { Rosemary C. Reilly, } \\
\text { PhD, MEd }\end{array}$ & $\begin{array}{l}\text { Transformative } \\
\text { paradigm }\end{array}$ & $\begin{array}{l}\text { Reality is the product of } \\
\text { critical interpretation that } \\
\text { aims to transform the } \\
\text { social world in order to } \\
\text { emancipate marginalized } \\
\text { groups or communities. }\end{array}$ & $\begin{array}{l}\text { The knowledge is ideo- } \\
\text { logically oriented, and the } \\
\text { focus is empowering in its } \\
\text { goal. }\end{array}$ & $\begin{array}{l}\text { Qualitative method is privileged. } \\
\text { Participants to the research } \\
\text { are experts into the underly- } \\
\text { ing causes of the issues within } \\
\text { their social world. }\end{array}$ \\
\hline
\end{tabular}




\section{Yin: Postpositivism}

Yin's realist-postpositivist epistemological posture ${ }^{1,13}$ defines a case study as "an empirical inquiry that investigates a contemporary phenomenon (the 'case') within its real-life context."14 Although reality cannot be entirely apprehended, the knowledge generated from the case study is the result of the combination of experimentations leading to a closer approximation of actual mechanisms. ${ }^{15}$ Yin suggests combining quantitative and qualitative sources, viewing them as equally instrumental. He places considerable emphasis on preparing a detailed design at the outset of the research and advises that investigators make only minor changes in the design after they begin data collection. ${ }^{16}$ Interaction with research participants therefore needs to be minimized and subjectivity managed to avoid biasing the results. ${ }^{16}$

\section{Stake: Constructivism}

Stake's epistemological commitment is to constructivism, which leads him to define the case study as the "study of the particularity and complexity of a single case, coming to understand its activity within important circumstances." ${ }^{17}$ Unlike Yin, Stake considers knowledge as a construction rather than the result of an empiric inquiry developed within a logical sequence. He argues that reality is multiple and subjective. ${ }^{17}$ This assertion implies that human experiences can be known through every perspective of a given situation, all of which are equally valuable. While suggesting that every viewpoint of a situation be represented in the case study, he recommends minimal interaction between the researchers and the context of the case or the involved individuals. ${ }^{18}$

\section{Merriam: Constructivist Pragmatism}

Merriam's constructivist pragmatism appears similar to Stake's at the outset. Reality is an intersubjective construction. ${ }^{19}$ Where she diverges from Stake is mostly in the finality of knowledge, which is to address concrete problems and give answers or direction to progress. ${ }^{15}$ In this perspective, the truth is what works in practice. ${ }^{15}$ Merriam's approach to case study design combines elements of Yin's positivist standpoint with Stake's constructivism. For her, a case study is essentially an in-depth description and analysis of a bounded system..$^{19}$ Merriam proposes a structured approach to designing research in a step-by-step process: conducting a literature review; constructing a theoretical framework; identifying a research problem; crafting and sharpening research questions; and selecting the sample (purposeful sampling). ${ }^{19}$

Yet, Merriam recommends that the study design remain flexible to a certain degree, which means, for example, that sample selection may occur before or in conjunction with data collection. ${ }^{16}$ As it is the unit of analysis that defines the case, other types of approaches can be combined with the case study. ${ }^{19}$ The design will depend on the theoretical framework of the study, its purpose, and the research questions. ${ }^{19}$ In Merriam's constructivist pragmatism, participatory research is an approach to enhance internal validity. ${ }^{16}$ This epistemological posture is compatible with a participatory approach to case study research.

\section{THE WHY AND HOW OF USING A CASE STUDY WITH A PARTICIPATORY APPROACH IN IMPLEMENTATION RESEARCH}

Which case study approach should be used in implementation research? The answer will depend on the epistemological assumptions on which the methods will rely. On one hand, a research team adopting a postpositivist standpoint (as proposed by Yin) will want to maintain independence from stakeholders and will conduct the implementation analysis from an external/objective point of view that precludes a participatory approach. On the other hand, a team adopting a constructivist perspective (as proposed by Stake) will plan qualitative methods to shed light on the multiple perspectives of stakeholders without involving them as co-researchers in the study. Then again, researchers who adopt a transformative posture (as proposed by Reilly) will work closely with community or organizational partners in the co-construction of the implementation using a participatory case study approach. Finally, a "middle ground" approach ${ }^{20}$ may be to adopt a pragmatic posture (as proposed by Merriam), where researchers use a case study with a participatory approach to conduct an implementation analysis of a health care innovation while consulting community or organizational stakeholders in certain phases of the research. Adopting this epistemological posture, we will present the example of the PriCARE program $^{5,6}$ in the next section.

\section{TWELVE STEPS FOR CONDUCTING CASE STUDIES WITH A PARTICIPATORY APPROACH IN HEALTH CARE IMPLEMENTATION RESEARCH}

Building on Merriam's previously mentioned step-bystep process, ${ }^{19}$ we propose 12 steps for conducting case studies with a participatory approach in health care implementation research. Figure 1 illustrates the proposed research process. Steps 1 through 10 are sequential and iterative, whereas steps 11 and 12 are concurrent and ongoing. 


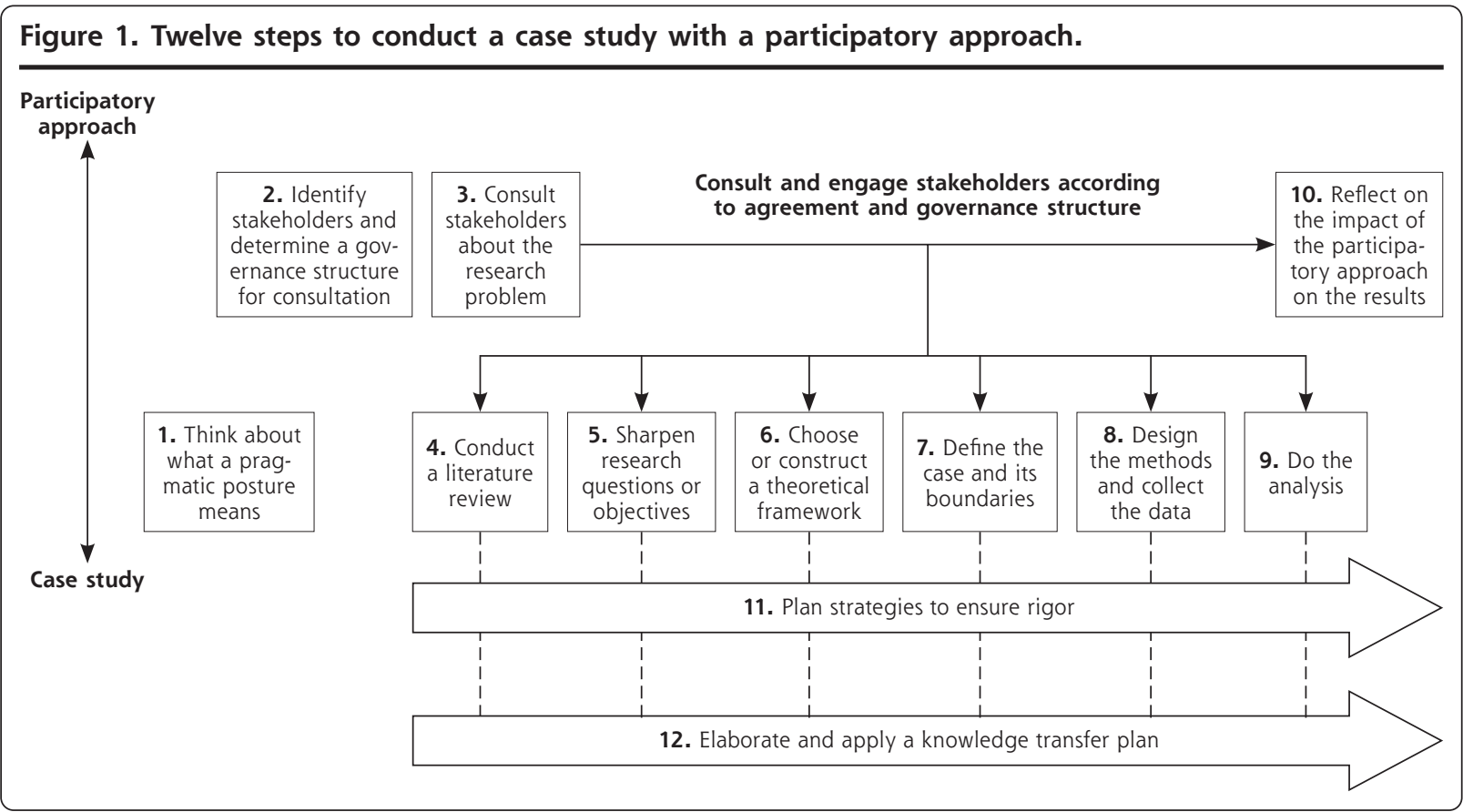

\section{(1) Think About What a Pragmatic Posture Means}

Disagreements during the project within the academic research team, or between the academic research team and stakeholders, may be related to differences of epistemological posture or values. Being aware of and sharing this posture from the beginning of the project will help maintain the coherence of methodological choices throughout the project. For the PriCARE program, in accordance with the pragmatic posture of Merriam, the academic research team decided on consultation of varying intensity, rather than full partnership, depending on the category of stakeholders.

\section{(2) Identify Stakeholders and Determine a Governance Structure for Consultation}

To optimize the implementation process and practice changes, various stakeholders-decision makers, clinicians, and patient partners-may collaborate with the academic research team according to their interest, availability, and expertise. In PriCARE, decision makers and clinicians were consulted based on the relevance of their expertise to certain phases of the project, and to accommodate time constraints, whereas most patient partners were engaged as co-researchers in all steps of the project. Many stakeholders were involved before the grant was obtained and in a pragmatic context (people changing jobs or people expressing interest in being involved), whereas other stakeholders joined the team during the project (new patient partners, new case managers, etc). Supplemental Table 1 (available at https://www.AnnFamMed.org/lookup/suppl/ doi:10.1370/afm.2717/-/DC1) identifies the committees and roles of stakeholders within the PriCARE program.

Four types of stakeholders were involved corresponding to the categories proposed by Damschroder et $\mathrm{al}^{21}$ in their Consolidated Framework for Implementation Research (Supplemental Figure 1, available at https://www.AnnFamMed.org/lookup/suppl/ doi:10.1370/afm.2717/-/DC1). Their roles and contributions are detailed below.

Opinion leaders. Decision makers, who are referred to as opinion leaders, ${ }^{21}$ are in a good position to inform the team regarding the broad context of implementation and to play a role in disseminating results and applying new knowledge. In the PriCARE program, decision makers were health center chief executive officers, primary care services directors, and representatives of health ministries. The academic research team consulted decision makers from each participating province while writing the grant request to ensure consideration of the global context in which the project would be implemented. Decision makers were consulted for strategic decisions and for knowledge transfer activities.

Champions. As champions, ${ }_{1}^{21}$ clinicians working on the ground are usually aware of the specific dynamics in their setting and can give useful advice to the research team regarding feasibility, potential challenges, or adaptation required before implementation. Champions can be helpful in convincing their colleagues to participate in the project and in encouraging them toward change. The academic research team 
was in contact, in person or by telephone, with family physicians as well as managers in the clinics to facilitate case management implementation.

Formally appointed internal implementation leaders. Individuals from within the organization who have been formally appointed with responsibility for implementing the intervention - as a part of their job-are called formally appointed internal implementation leaders. ${ }^{21}$ In PriCARE, the case manager nurses were identified during recruitment of the participating clinics at the beginning of the project. In addition to doing fieldwork, they informed the academic research team about the challenges they were facing or about what helped them to carry out the intervention as the project was progressing. The academic research team organized formal training and a virtual community of practice bringing all case managers together to deploy codevelopment activities.

External change agents. Finally, patient partners may play the role of external change agents. ${ }^{21}$ They bring an experiential perspective to research, provide valuable advice to the team about patient recruitment and data collection, and validate and interpret aspects of the analysis. In PriCARE, regular meetings with patient partners (not related to the clinics) and research assistants were organized to advise the team on different aspects of the project (questionnaires, patient recruitment, analysis, knowledge transfer plan, etc). Patient partners also contributed to training the case managers and met with them to advise them on approaching patients with complex needs.

Discussions with stakeholders addressed expectations and preferences regarding their contribution, as well as the management of interaction, engagement, and communication. A clear governance structure was proposed (Supplemental Figure 1). Most communication was virtual and by e-mail to accommodate geographic realities. The way the team functioned always considered the various circumstances of different stakeholders, their level of involvement, and their ability to contribute during the project.

\section{(3) Consult Stakeholders About the Research Problem}

PriCARE decision makers and clinicians in each province helped the academic research team to understand their context of implementation and what was needed in that province in terms of adapting the intervention and training. We also consulted patient partners to develop a broader understanding of the problem.

\section{(4) Conduct a Literature Review}

The literature review determines the knowledge gap, which in turn allows the relevant research questions to be presented and specified for the project. In PriCARE, 2 literature reviews on case management were conducted: a systematic review by the academic research team ${ }^{22}$ and a realist synthesis by the research team engaging stakeholders in the steering committee, including decision makers, clinicians, and patient partners. ${ }^{23}$ Both reviews were summarized and shared with stakeholders.

\section{(5) Sharpen Research Questions or Objectives}

The final research questions of the PriCARE program were formulated, after consultation with stakeholders, by the academic research team. They are as follows: what are the facilitators of and barriers to case management implementation in primary care clinics across Canada; what are the relationships between the actors, contextual factors, mechanisms, and outcomes of the case management intervention; and what are the next steps toward case management scale-up in primary care across Canada?

\section{(6) Choose or Construct a Theoretical Framework}

A theoretical framework emerging from the literature review helps elaborate research questions and points of emphasis. ${ }^{24}$ It also often helps in the building of data collection tools (eg, interview guides and questionnaires) and in guiding the analysis process. Although stakeholders may contribute to this step, in PriCARE, it was the academic research team who decided to use a combination of the Consolidated Framework for Implementation Research ${ }^{21}$ and the Rainbow Model of Integrated Care Framework, ${ }^{25}$ combining the concepts of primary care and integrated care. ${ }^{6}$ The academic research team took responsibility for explaining theoretical frameworks to stakeholders through brief, informal online meetings, to ensure a common comprehension and facilitate participation and engagement of all stakeholders throughout the research process.

\section{(7) Define the Case and Its Boundaries}

In implementation research, the case is often an innovation implemented in a specific primary care setting. To select the case and establish the research design, we recommend identifying the focus and refining the parameters of the case including the participants, location, and/or process to be explored, and also establishing the timeframe for investigating the case. ${ }^{19}$ The focus and boundaries may also be influenced by the resources and time available to accomplish the research project. In PriCARE, stakeholders, especially opinion leaders and champions, helped delimit the cases. Each case was the case management intervention implemented in the individual clinic. 


\section{(8) Design the Methods and Collect the Data}

We encourage researchers to use multiple methods of data collection to provide a more comprehensive view of the subject being studied. Data collection methods for case studies are usually qualitative but may also be quantitative. ${ }^{1}$ Use of software is highly recommended for regrouping and managing all the data..$^{9,15}$ The complete design and data collection methods of PriCARE, which had a multiple-case, embedded, mixed methods design, are described elsewhere. ${ }^{5,6}$ The research team designed the methods. Clinicians and case managers identified eligible patient participants registered to the clinic, who were contacted by the latter. Patient partners, well positioned to understand the situation of participants, contributed to explaining the research project in lay language, and to answering their questions to obtain their consent for participation. They were also involved in developing recruitment and data collection tools to adapt the scientific language to a lay audience.

Case study research with a participatory approach allowed the PriCARE academic research team to observe participants during meetings with stakeholders. The academic research team carefully planned interactions to manage key messages to be delivered to stakeholders and to record and document all interactions so that meetings were also opportunities for data collection, for promoting change, and for facilitating implementation. The impact of this approach on data collection and results must be rigorously documented, analyzed, and discussed. ${ }^{9,26}$

\section{(9) Do the Analysis}

Although the various analytic strategies suggested by the 3 methodologists ${ }^{13,19,27}$ remain relevant, the particulars of case studies with a participatory approach make it possible to involve partners in various steps, to better understand, to coanalyze, or to validate results. In PriCARE, patient partners participated in key steps of the analysis to ensure meaningful interpretation.

\section{(10) Reflect on the Impact of the Participatory Approach on the Results}

The case study with participatory approach should document the role of the research team during observation and consider it to be a contextual element in the analysis of each case. For example, positive relationships between the individuals involved in a case may promote implementation and improve impact. ${ }^{28}$ This situation may differ with another group of individuals in another case. Although such facilitation is considered a desirable extra benefit of the participatory approach, its impact on the results still has to be made explicit and discussed. ${ }^{8}$
In PriCARE, the research team used a logbook to document interactions and reflections to maintain a reflexive distancing. ${ }^{9,19}$ We sought to involve all stakeholders in these reflections, to better understand the impacts of the participatory approach, both positive and negative, which were transparently discussed in reports or articles.

\section{(11) Plan Strategies to Ensure Rigor}

As a concurrent, ongoing step, the team has to plan strategies to ensure the rigor of the research. ${ }^{29}$ In PriCARE, we ensured credibility through in-depth description and analysis of context using qualitative and quantitative data collection in each province. We kept an audit trail of all decisions and collected data to ensure dependability. We promoted triangulation of the expertise of team members (researchers of various backgrounds, diverse health care professionals, patient partners, decision makers) and reflexivity through team discussions and interactions. We made a thick description of each clinic's context to promote transferability. We also respected rigor criteria when administering questionnaires. ${ }^{30}$

\section{(12) Elaborate and Apply a Knowledge Transfer Plan}

Researcher and stakeholder collaboration throughout the research process is a strong predictor that research findings will be put into practice, ${ }^{31}$ so stakeholders should be involved in the elaboration and the application of the knowledge transfer plan. In PriCARE, team members and stakeholders of each province representing each targeted audience (population, clinicians, decision makers, and researchers) helped to write the plan throughout the study, tailor messages, and disseminate case study findings. ${ }^{31}$ All stakeholders mobilized within the case study contributed to knowledge transfer.

\section{CONCLUSIONS}

Engaging stakeholders in the design and conduct of case studies may enhance implementation analysis of complex health care interventions in primary care, whereby stakeholders are consulted to foster translation of findings results into practice. Ensuring transparency and rigor of the approach remains crucial as it lays the groundwork for critical evaluation of this strategy. The 12 steps we propose here constitute a major milestone toward attaining this goal. Future research could contribute to testing and refining these steps, and demonstrating the contribution of this approach to implementation in health care.

To read or post commentaries in response to this article, go to https://www.AnnFamMed.org/content/19/6/540/tab-e-letters. 
Key words: case study; participatory approach; implementation; health care innovation; change, organizational; health services research; primary care

Submitted July 10, 2020; submitted, revised, February 11, 2021; accepted March 15, 2021.

Authors' contributions: C.H. proposed a first draft of the manuscript. C.H., M-C.C., M.B., A.D., M.K., A.G., P-L.B., and M.L. substantially contributed to subsequent drafts. All authors read and approved the final manuscript.

Funding support: This work was supported by the Canadian Institutes of Health Research (CIHR).

Disclaimer: The views expressed are solely those of the authors and do not necessarily represent official views of the authors' affiliated institutions or funder.

Acknowledgments: We would like to acknowledge all team members and partners who were engaged in the PriCARE program.

Supplemental materials: Available at https://www.AnnFamMed. org/lookup/suppl/doi:10.1370/afm.2717/-/DC1.

\section{References}

1. Harrison H, Birks M, Franklin R, Mills J. Case study research: foundations and methodological orientations. Forum Qual Soc Res. 2017;18(1).

2. Crowe S, Cresswell K, Robertson A, Huby G, Avery A, Sheikh A. The case study approach. BMC Med Res Methodol. 2011;11(100):100.

3. Champagne F, Brousselle A, Hartz Z, Contandriopoulos A, Denis J. L'analyse de l'implantation. In: Brousselle A, Champagne F, Contandriopoulos A, Hartz Z, eds. L'évaluation: Concepts et Méthodes. Presses de l'Université de Montréal; 2011:237-273.

4. Canadian Institutes of Health Research, Government of Canada. Knowledge user engagement. Published May 11, 2020. Accessed Aug 2, 2021. https://cihr-irsc.gc.ca/e/49505.html

5. Hudon C, Chouinard MC, Aubrey-Bassler K, et al. Case management in primary care for frequent users of healthcare services with chronic diseases and complex care needs: an implementation and realist evaluation protocol. BMJ Open. 2018;8(11):e026433.

6. Danish A, Chouinard MC, Aubrey-Bassler K, et al. Protocol for a mixed-method analysis of implementation of case management in primary care for frequent users of healthcare services with chronic diseases and complex care needs. BMJ Open. 2020;10(6):e038241.

7. Cargo M, Mercer SL. The value and challenges of participatory research: strengthening its practice. Annu Rev Public Health. 2008; 29:325-350.

8. Macaulay AC, Jagosh J, Seller R, et al. Assessing the benefits of participatory research: a rationale for a realist review. Glob Health Promot. 2011;18(2):45-48.

9. Creswell JW, Poth CN. Qualitative Inquiry \& Research Design: Choosing Among Five Approaches. 4th ed. SAGE Publications; 2018.

10. Reilly RC. Participatory case study. In: Mills A J, Durepos G, Wiebe E, eds. Encyclopedia of Case Study Research. SAGE Publications; 2010: 658-660.

11. Craig P, Dieppe P, Macintyre S, Nazareth I, Petticrew M. Developing and Evaluating Complex Interventions: New Guidance. Medical Research Council; 2019.
12. Creswell JW. Qualitative Inquiry \& Research Design. 2nd ed. SAGE Publications; 2007.

13. Yin RK. Case Study Research and Applications: Design and Methods. 6th ed. SAGE Publications; 2018.

14. Yin RK. Case Study Research: Design and Methods. SAGE Publications; 2014.

15. Patton MQ. Qualitative Research \& Evaluation Methods: Integrating Theory and Practice. 4th ed. SAGE Publications; 2015.

16. Yazan B. Three approaches to case study methods in education: Yin, Merriam, and Stake. Qual Rep. 2015;20(2):134-152.

17. Stake RE. The Art of Case Study Research. SAGE Publications; 1995.

18. Abma TA, Stake RE. Science of the particular: an advocacy of naturalistic case study in health research. Qual Health Res. 2014;24(8): 1150-1161.

19. Merriam SB, Tisdell EJ. Qualitative Research: A Guide to Design and Implementation. 4th ed. John Wiley \& Sons; 2016.

20. Chen HT. Interfacing theories of program with theories of evaluation for advancing evaluation practice: reductionism, systems thinking, and pragmatic synthesis. Eval Program Plann. 2016;59:109-118.

21. Damschroder LJ, Aron DC, Keith RE, Kirsh SR, Alexander JA, Lowery $J C$. Fostering implementation of health services research findings into practice: a consolidated framework for advancing implementation science. Implement Sci. 2009;4:50.

22. Hudon C, Chouinard MC, Pluye $P$, et al. Characteristics of case management in primary care associated with positive outcomes for frequent users of health care: a systematic review. Ann Fam Med. 2019; 17(5):448-458.

23. Hudon C, Chouinard MC, Aubrey-Bassler K, et al. Case management in primary care for frequent users of health care services: a realist synthesis. Ann Fam Med. 2020;18(3):218-226.

24. Merriam SB. Qualitative Research and Case Study Applications in Education. 2nd ed. Jossey-Bass Publishers; 1998.

25. Valentijn PP, Schepman SM, Opheij W, Bruijnzeels MA. Understanding integrated care: a comprehensive conceptual framework based on the integrative functions of primary care. Int J Integr Care. 2013;13:e010.

26. Morse J. Reframing rigor in qualitative inquiry. In: Denzin NK, Lincoln YS, eds. The SAGE Handbook of Qualitative Research. 5th ed. SAGE Publications; 2017:796-817.

27. Stake RE. Multiple Case Study Analysis. The Guilford Press; 2006.

28. International Collaboration for Participatory Health Research (ICPHR). Position Paper 1: What is Participatory Health Research? International Collaboration for Participatory Health Research; 2013.

29. Forero R, Nahidi S, De Costa J, et al. Application of four-dimension criteria to assess rigour of qualitative research in emergency medicine. BMC Health Serv Res. 2018;18(1):120.

30. Cook DA, Beckman TJ. Current concepts in validity and reliability for psychometric instruments: theory and application. Am J Med. 2006; 119(2);166e7-166e16.

31. Lavis JN, Posada FB, Haines A, Osei E. Use of research to inform public policymaking. Lancet. 2004;364(9445):1615-1621. 